\title{
The perceptions of community-based organizations collaborating with nursing faculty to promote students' public health nursing competencies
}

\author{
Mélanie Lavoie-Tremblay*1, Françoise Filion ${ }^{1}$, Thalia Aube ${ }^{1}$, Guylaine $\mathrm{Cyr}^{1}$, Geneviève Laporte ${ }^{2}$ \\ ${ }^{1}$ Ingram School of Nursing, McGill University, Canada \\ ${ }^{2}$ Faculty of Nursing, University of Montreal, Canada
}

Received: March 26, 2020

DOI: $10.5430 /$ jnep.v10n8p58

\author{
Accepted: May 5, 2020 \\ Online Published: May 18, 2020 \\ URL: https://doi.org/10.5430/jnep.v10n8p58
}

\begin{abstract}
Collaborative community-based organizations (CBOs) and academic partnerships are a prerequisite for the creation of quality learning environments for undergraduate nursing students. However, the explicit nature of the relationship between academic and CBO partners is not as well-defined as the one between hospitals and their clinical settings. The aim of this study was to describe and evaluate the implementation and impact of a 3-year-long partnership between a nursing school and 20 different CBOs. Semi-structured individual interviews were conducted with 11 CBO partners throughout June and July of 2018. Interview questions explored the collaborative process, its benefits, and areas for improvement. Study participants reported that the partnerships brought several benefits, including familiarizing students with marginalized populations, demystifying the health care system for the populations served by the CBOs, and the students' development of sustainable health promotion tools that contributed positively to the CBOs' overall mission. Challenges identified by the CBOs included finding resources to provide adequate student supervision and population access, and some students' challenges with adapting to the CBOs' client population or community environment. Collaborative partnerships were mutually beneficial for populations, students and the community organizations. These results support the establishment and long-term development of these types of partnerships.
\end{abstract}

Key Words: Community-academic partnerships, Service-learning, Nursing clinical education, Community health nursing

\section{INTRODUCTION}

For nursing education institutions who want to provide quality learning environments, partnering with community-based organizations (CBOs) is a way to allow student nurses to encounter marginalized populations and to develop professional competencies for working with them. However, the literature shows that these partnerships are only mutually beneficial to CBOs when both parties follow discussed guidelines, utilize relationship-focused processes, and produce meaningful outcomes and multi-level transformations ${ }^{[1]}$ that relate to the expectations and commitments of the partnership. As a result, authentic and collaborative community-academic partnerships (CAPs) can be difficult to sustain and thus are not well-described within the literature. This article aims to address this gap by describing the collaborative partnership process between a Canadian university's School of Nursing and several Montreal-based CBOs. This study also seeks to evaluate the effects of those sustainable partnerships within

\footnotetext{
*Correspondence: Mélanie Lavoie-Tremblay; Email: Melanie.lavoie-tremblay @ mcgill.ca; Address: Ingram School of Nursing, McGill University,
} Canada. 
the communities involved.

There is a question whether institutions that educate health care professionals in public health and that have a service mandate to address social justice-related health care issues are making enough efforts to reach underserved populations. For nursing schools, formal partnerships with CBOs and student clinical placements within CBOs are uncommon. ${ }^{[2,3]}$ Health care challenges in the 21 st century will require nurses to move from hospital-based models of care that emphasize acute care competencies to models centered on health promotion and disease prevention within the community. ${ }^{[2]}$ By recruiting CBOs to become collaborators in nursing education, nursing schools can strive to achieve their social justice commitments aimed at developing nurses as global citizens. ${ }^{[4]}$

As nurses are vital contributors to health promotion and disease prevention efforts, nurse educators have a responsibility to prepare students for engaging effectively with different communities. ${ }^{[5]}$ Teaching approaches which utilize community environments as a pedagogical platform create opportunities for students to view health care provision holistically. Students can discover the context of health care policy, cultural differences in health care beliefs and nutrition and hygiene practices, and the barriers that some populations experience in accessing health care services. ${ }^{[2,3,6]}$ Through these community partnerships, students are provided with real-life educational experiences that promote better preparation for improving nurse capacity. ${ }^{[7]}$

\section{REVIEW OF THE LITERATURE}

\subsection{Community-based organizations}

CBOs provide highly-valued services to members of their community. The term itself encompasses similar organizations such as civil society or non-governmental organizations. ${ }^{[8]}$ CBOs often support the most marginalized populations, those who are disadvantaged or stigmatized within society. CBOs are well-positioned to serve these populations, as they understand their local community. They are committed to a social justice agenda and take on political and advocacy roles within their communities. ${ }^{[8]}$

As partners to academic institutions, CBOs provide invaluable access to populations that may not utilize regular avenues for accessing health care services. It is through these community environments that students can learn about the health disparities experienced by marginalized populations and understand the nurse's role in addressing social determinants of health. ${ }^{[2]}$ Furthermore, community placements can provide students with unique experiences that enhance their understanding of healthcare provision and its challenges, including the nature of professional relationships between providers and consumers. ${ }^{[2]}$ Members of CBOs are key individuals in implementing these partnerships, as they possess essential firsthand knowledge of the community and its priority public health concerns. This information is crucial for designing and implementing evidence-based projects. ${ }^{[9]}$

\subsection{Community-academic partnerships}

Community-academic partnerships involve connecting the resources of a university with high-priority social, civil and ethical concerns within community settings. ${ }^{[10]}$ These partnerships may be defined as "the coming together of diverse interests and people to achieve a common purpose via interactions, information sharing and coordinated activities." $[11,12]$ Beal $^{[12]}$ identifies potential mutual benefits for both partners from the establishment of a CAP. These include increased visibility for nursing contributions to health care delivery, maximization of resources, opportunities for educators to remain current in practice, the delivery of cost-effective quality care, education of students and staff, and increased research productivity. ${ }^{[12]}$

When establishing CAPs, there are challenges that exist for both partners. For the university, there may be an inadequate understanding about the benefits that collaboration may offer, a limited level of faculty members coordinating the collaboration process, and a limited amount of available incentives such as grants or rewards for conducting the partnerships and/or research. Additionally, community engagement has generally been undervalued for university review and promotion, further discouraging those working in academia. ${ }^{[13]}$ Community members may also be hesitant to form partnerships if they feel that the projects and academic commitments to the institution are irrelevant to their needs. ${ }^{[13]}$ Often what is needed are more mutually-beneficial partnerships that extend beyond semester-based programs towards a sustainable model with the larger purpose of guiding the partnership in the long-term.

Mayer ${ }^{[14]}$ et al.'s recommendations for establishing a sustainable CAP include:

(a) Developing a joint mission and strategic plan

(b) A partnership structure that clearly defines roles, expectations and communication channels

(c) Increased duration of engagement to allow for meaningful learning experiences and community benefit

(d) Adequate and shared leadership, accountability, resources and rewards between organizations

According to Beal's review, ${ }^{[12]}$ specific strategies for sustaining partnerships between academic institutions and community organizations include written, formalized and measur- 
able goals with ongoing evaluation, articulated leadership support, structured accountability, shared resources, and dedicated time. CAPs and their programs also require evaluation. Evaluation is essential for ensuring the interventions are meeting identified needs and providing a strong evidence base for sustainability. ${ }^{[15]}$ However, these outcomes remain unknown due to the insufficient structures for both identifying and measuring outcomes specific to these community settings and the populations they serve. ${ }^{[3]}$ Other authors ${ }^{[3,7]}$ agree that outcomes cannot be evaluated without clear planning and outcome measures. For nursing schools, evaluation of community placements tends to focus primarily on student learning objectives rather than understanding the impact of services provided. It is recommended that both parties be equal players in the evaluation and presentation of the results of each project. ${ }^{[16]}$

\subsection{Description of student projects and curriculum}

Within the context of a final-year undergraduate communitybased nursing course for students, nursing students are asked to collaboratively develop, implement and evaluate a community health promotion project with an assigned $\mathrm{CBO}$ within a 12-week timeframe. The academic objective is to demonstrate the Entry-to-Practice Public Health Nursing Competencies for Undergraduate Nursing Education ${ }^{[17]}$ through public health (population) nursing practice centered on health promotion and prevention within the community. Fourteen hours are dedicated to the practicum each week.

These voluntary partnerships, which were formed by the School of Nursing and various community-based organizations on the island of Montreal, are aimed at strengthening the community service mandates of the CBOs and contributing to the academic service mandate. The partnerships facilitate opportunities for nursing students to learn about social justice issues such as the existing health disparities for various marginalized populations. In addition, students learn about nurses' role in addressing issues such as improving access to care and other social determinants of health.

To achieve these course objectives, student teams of four to seven students are required to apply the Entry-to-Practice Public Health Nursing Competencies for Undergraduate Nursing Education ${ }^{[17]}$ to collaboratively develop, implement and evaluate a health promotion or primary prevention project integrating the Population Health Promotion Model (PHPM) ${ }^{[18]}$ Students are expected to recruit sufficient resources to fund all team health promotion products (posters, pamphlets, resource materials) created for the project. Students are also asked to create incentives to promote increased client participation within their $\mathrm{CBO}$ environment. In addition, they are required to share their project evaluation results, recommendations and sustainability strategies with their CBOs, thereby reinforcing the principles of a mutually beneficial partnership. All projects are required to have measurable short-term outcome objectives linked to an agreedupon health promotion goal and to demonstrate an ethical alignment with the communities' values and goals.

\subsection{Population health promotion model}

When designing their projects, nursing students are asked to base the rationale of their interventions on the Population Health Promotion Model developed by Hamilton and Bhatti in 1996. ${ }^{[18]}$ This integrated, three-dimensional model helps its users to improve the health status of populations and address health inequities within them by identifying the who, what, and how of health promotion initiatives.

In a 1996 report, the Federal, Provincial and Territorial Advisory Committee on Population Health included in their definition of population health that it was influenced by different socio-economic factors such as education, gender, culture, and childhood development. ${ }^{[19]}$ These factors are better known as determinants of health (DoH). The revised version of the PHPM in 1999 by Flynn ${ }^{[20]}$ includes a total of 12 determinants of health: income and social status, work and working conditions, social support networks, personal coping skills, healthy child development, physical environments, social environments, education, genetic endowment, health services, culture, and gender. The DoH are represented by the first face of the three-dimensional model and provide the answer to the "what" of the project.

On the second face of the three-dimensional model are the action strategies, the "how" of intervening with different populations. Areas of action taken to enhance population health have been defined under the Ottawa Charter and were reintroduced in the PHPM. Areas of action include building healthy public policy, strengthening community action, creating supportive environments, developing personal skills, and reorienting health services. Multiple strategies are often used concurrently to optimize the effects of a community project initiative and are directly linked to the DoH targeted by the project.

The top face of the PHPM illustrates the level at which the action will take place. This face refers to the different levels of the social-ecological model: individual, family, community, structural, and society. It defines the audience of the community project and guides the choice of action strategies to be implemented for a successful initiative.

At the base of the cubic model, the fundamental elements to evidence-based decision-making are listed: research, experiential learning and evaluation. This side of the model ensures 
the validity and effectiveness of the community initiatives and supports informed decision making by policymakers to develop well-structured initiatives.

\subsection{Student projects}

The students' health promotion projects developed within the last three years (since January 2015) were reviewed for trends in terms of what DoH were selected. The project review also sought to determine priority community-based issues, as identified by the CBOs and the student teams. The action strategies from the PHPM that were integrated to develop the projects were also analyzed. For each project, students could target as many DoH as they found relevant within the context of their population, environment and priority health issues. To develop their projects, nursing students were asked to base the rationale of their interventions on the PHPM. ${ }^{[18]}$

The most targeted DOH were education (98 occurrences in 133 projects), personal health practices and coping skills (95 occurrences in 133 projects), and social support networks (59 occurrences in 133 projects). As for the identified priority issues, 37 of the 133 projects related to health education. Health education consisted of providing information to the population about relevant health issues such as sex education, sleep hygiene, and safe footcare practices, with the goal of improving knowledge on these topics.

Psychosocial education was selected in an almost equal proportion of projects (36 out of 133). These initiatives included promoting self-care activities, destigmatizing mental health issues, managing anxiety, stress and anger management, and providing peaceful conflict resolution strategies. The mostused strategies were developing personal skills and creating supportive environments (113 occurrences in 133 projects), followed by strengthening community action and developing personal skills (8 occurrences in 133 projects).

Only one project aimed at reorienting health services and one project looked at building public health policy. The public health policy project aimed to enhance knowledge about cannabis use among adolescents aged 13-18 years-old at a community resource center in the Montreal area. Using a harm reduction approach, the students employed the game of Jeopardy! to share information in an interactive way. To promote further knowledge dissemination, participants were also provided with a pamphlet to take home. The priority issue of this project was health education, and the DoH targeted included education, physical environments and personal health practices and coping skills. This project was implemented integrating two strategies, namely developing personal skills and creating a supportive environment.

Published by Sciedu Press

\section{METHODS}

\subsection{Study aim}

The aim of this study was to describe the implementation and evaluate the effects of a 3-year sustainable partnership between a Canadian School of Nursing and 20 urban community-based organizations (CBOs).

\subsection{Design}

A qualitative-descriptive design was used.

\subsection{Participants}

Participants were the School of Nursing's community partners at various CBOs.

\subsection{Sampling technique and inclusion criteria}

A convenience sampling approach was used to recruit 11 participants from 10 CBOs throughout June and July of 2018. An email invitation was sent from the research assistant to the CBOs' key contact (e.g., a supervisor or coordinator). The only inclusion criterion for partners was to be involved in the undergraduate community-based course at the School of Nursing for a minimum of 3 years. The exclusion criterion was to be involved in the undergraduate community-based course at the School of Nursing for less than 3 years. The average length of partnership was 6 years (3-10 years) and the average number of nursing students assigned on a yearly basis was 14 (4-30). The number of employees working in the 10 participating community organizations averaged 42 , ranging from 8 to 150 . The types of marginalized populations served by the 10 organizations were those with mental or behavioral issues, people experiencing homelessness or lacking a stable place to live, people living with addiction issues or substance abuse disorders, Indigenous Canadians, people with one or more chronic health conditions, people from the lesbian, gay, bisexual, queer, or transgender (LGBQT) community, children, people from migrant populations, racial or ethnic minorities, the elderly, low-income families and people who had experienced domestic or spousal violence.

\subsection{Ethical considerations}

Ethical approval for the study was obtained from the Institutional Review Board of the Faculty of Medicine (A05-E2818B). The interviewer reviewed the consent form with each participant and written consent was obtained from all participants before beginning the interview. The consent form informed participants about the study procedure, the purpose of the study, and that their participation was voluntary. The consent form also explained the right to withdraw at any time, and the measures that would be taken to ensure confidentiality. 


\subsection{Data collection}

Semi-structured individual interviews were conducted during work hours at a location convenient to the participant. All interviews were conducted by a research assistant, with each interview lasting approximately 30-40 minutes. Interviews were conducted in either English or French, and each interview was audio-recorded and transcribed. A semistructured interview guide was used. The main themes addressed included the partnership process, benefits and area for improvements based on Authentic Partnership Framework. ${ }^{[3]}$ This framework asserts that mutual decision making, shared goals, reciprocity, meeting agency and addressing community needs as required factors for healthy CAPs. ${ }^{[3]}$ To gain background information about the participants, a socio-demographic questionnaire was completed by each participant at the end of the interview.

\subsection{Analysis}

The data generated by open-ended questions were analyzed using a method proposed by Miles and Huberman. ${ }^{[21]}$ This method of qualitative data analysis consists of three concurrent streams of activities: condensing the data, data display, and elaboration and verification of the data. Original data was condensed by generating codes and categories. ${ }^{[21]}$ Open coding occurred as the researcher reviewed transcripts and field notes line-by-line, highlighting and extracting sections that touched the participants' perceptions. Categories were then formed by clustering codes which referred to similar concepts. Elaboration and verification of the data was done through discussion and review between researchers. Descriptive statistics were generated through Excel to describe the socio-demographics of the sample.

\section{FINDINGS}

Participants' responses were analyzed, and several common themes were identified in the participants' comments related to the benefits, challenges and sustainability of the partnership.

\subsection{Benefits}

\subsubsection{Understanding marginalized groups}

According to the participants, students substantially increasing their community knowledge was one of the main positive impacts of the partnership between a School of Nursing and urban CBOs. Student awareness of marginalized populations increased as they became immersed in the community settings, acquiring a more global vision of their health needs. Collaboration between students and underserved populations allowed students to better understand the realities and challenges experienced by these clients, but also their own strengths and capacities. These experiences served to chal- lenge preconceived notions students may have had prior to taking the course and facilitated information-sharing among peers to de-stigmatize these populations.

Main results. Well, the students get exposed to something they probably wouldn't otherwise... So by having future health care professionals spending time with... marginalized populations, it's sensitizing future health care professionals to a different reality (CBO8).

\subsubsection{Demystification of the health care system}

The demystification of the health care system was among the impacts described as being the most important. As stated earlier, contact with a marginalized clientele allowed the students to challenge their own prejudices by becoming a witness to the daily realities these clients experience. In return, from the perspective of $\mathrm{CBO}$ partners, connecting with students allowed their clients to become more familiar with the health care world. This may have served to demystify the medical system, potentially encouraging clients to be more open in seeking traditional health care services. Per the participants, building trust between the students and community population supported client engagement in health promotion discussions and their participation in the students' projects.

We work with people who are extremely reluctant to go to health services because reception is not always easy in the health services. Or, frankly, access is limited. At least 50\% of everybody we meet does not have a [provincial health insurance] card.... So often they self-medicate or they self-diagnose.... [Clients will say,] 'I searched on Google and it tells me this, that and the other.' God knows that there's not a shortage of disinformation in health! (CBO1).

\subsubsection{Health and nursing knowledge transfer}

The transfer of evidence-based health interventions, nursing knowledge and available resources from students to clients was another important impact of the collaboration. The students' knowledge strengthened the community partners' messages about health promotion and well-being that they wished to convey to their clients. Clients could then put into practice the shared information and access the suggested resources to improve their health status.

And this is why we like to keep the partnership going, because we feel that it's a win-win situation, right? [Students] come in, they provide us their expertise, and then they gain more knowledge with regards to this population (CBO9). 


\subsubsection{Health promotion tools}

Another important impact of the partnership was the development of tools and resources by the students. These tools were used, and in some organizations reused, by the stakeholders to support their future interventions with clients.

Tools like... posters, maps, things like that, with a good exploration of the surrounding resources.... it's like it's a toolkit ready to go.... It's really effective. And the advantage of this is that... it is tools that remain and that we can use with other clients (CBO2).

\subsection{Challenges}

\subsubsection{Student adaptation to community context and time constraints}

For the participants, the partnership posed several challenges for community organizations, including the need to occasionally work with students who had difficulty adapting to the organization's culture and the population they served. In some cases, students' interpersonal capacities required development in order to sensitively interact with clients. However, this challenge evolved into a strength if it pushed students to engage in independent learning and self-reflection to adapt to their practice contexts.

The negative impacts are when certain nursing individuals, let's say students, don't really understand the population or they haven't taken the time for whatever reason, they can be invasive. And that makes the residents uncomfortable... So they have to adjust that way too. And until they adjust, sometimes they can be invasive (CBO7).

\subsubsection{Limited time and human resources}

For members of the community organization, limited time and human resources to supervise students was also a challenge.

A challenge I see when embarking on a project like this one is to have the availability to support them in all stages of the project.... We are still a group of people with very busy agendas. So, sometimes, there is a bit of a challenge with that (CBO1).

\subsection{Sustainability}

The participants were insistent the collaborative program be kept in place, as it allowed them the important opportunity to sensitize future health care professionals to the lived experience and diverse needs of marginalized populations. These learning experiences also served to challenge pre-conceived notions held about these populations.

Published by Sciedu Press
I know that there's always this struggle with science and feelings... But at the end... they take care of a human... a more human approach will improve the health of a lot of people... But I really hope that with this kind of collaboration at least you will change a little bit the system (CBO6).

\subsection{Implications and Recommendations}

Nursing academic institutions are encouraged to continue their efforts to integrate a strong partnership with CBOs within their undergraduate nursing programs as a way to improve nurses' competencies in serving marginalized populations. From the point of view of the CBOs, partnerships with nursing schools are beneficial for all stakeholders. For nursing schools, formal partnerships with CBOs produce several benefits, including the diversification of the educational experience. For CBOs, the students bring additional expertise and their knowledge supports stakeholders' health promotion messages (prevention, health, and well-being) they wish to convey to their clients. Additionally, for the clients, the contact with nursing students allows them to become more familiar with and potentially more open to the health care system. The supported population also receives evidenced-based information about health promotion and access to available resources.

It is recommended that all members of the CBO team clearly understand the objectives of the partnership program and that efforts are made to familiarize nursing students with the clientele they serve. Students must be sufficiently prepared to respect the stakeholders' agendas, as well as the clients' needs throughout their health promotion project.

\subsection{Limitations and future research}

This study was limited in that it only captured the perceptions of the community and nursing school partners. As a result, the themes may not be the same ones that would have been produced from a study exploring the perceptions of students and clients. It remains to be seen if these partnerships have the same efficacy and benefits from the perspectives of the students and clients.

\section{Conclusion}

Partnerships between CBOs and nursing schools have the potential to mutually benefit nursing students, CBOs and their clients. Though these partnerships present some challenges for the various stakeholders involved, CAPs can support CBOs to achieve their community service mandate. Students provide a valued perspective, and develop resources 
to strengthen organizational capacity to address community challenges and improve care for marginalized populations.

By facilitating the unique access to these populations, these partnerships also provide students with valuable learning experiences in understanding how the social determinants of health influence community health. With clear expectations and process guidelines, partnerships such as the ones described in this study can be valuable tools for improving the quality of nursing education and the health care of Canadians.

\section{ACKNOWLEDGEMENTS}

The authors would like to acknowledge support from The
McGill Nursing Collaborative for Education and Innovation in Patient- and Family-Centered Care (Newton Foundation/McGill Faculty of Medicine) and Graphos/the McGill Writing Centre through the Writing for Publication initiative. The authors would also like to acknowledge the contributions of Diana Gausden, SCPHN, RN, Faculty Lecturer, Ingram School of Nursing, McGill University and Gib Primeau, MSW, Collaborative Coordinator, Ingram School of Nursing, McGill University.

\section{CONFLICTS OF INTEREST DisClosure}

The authors have disclosed no potential conflicts of interest, financial or otherwise.

\section{REFERENCES}

[1] Position statement on authentic partnerships [Internet]. Raleigh: Community-Campus Partnerships for Health Board of Directors. 2013 [cited July 5, 2019]. Available from: https ://www. ccphea lth.org/principles-of-partnership

[2] Ezeonwu M, Berkowitz B, Vlasses FR. Using an academiccommunity partnership model and blended learning to advance community health nursing pedagogy. Public Health Nurs [Internet]. 2014; 31(3): 272-80. PMid:24720659 https ://doi .org/10.1111/phn. 12060

[3] Voss HC, Mathews LR, Fossen T, et al. Community-academic partnerships: Developing a service-learning framework. J Prof Nurs [Internet]. 2015; 31(5): 395-401. PMid:26428344 https ://doi .or $\mathrm{g} / 10.1016 / \mathrm{j}$. profnurs .2015 .03 .008

[4] Wros P, Archer S. Comparing learning outcomes of international and local community partnerships for undergraduate nursing students. J Community Health Nurs [Internet]. 2010; 27(4): 21625. PMid:21058139 https://doi .org/10.1080/07370016.201 0.515461

[5] The Impact of an Academic/Community Partnership: Student Nurses' Experience of a Collaborative Health Promotion Project [online]. Whitireia Nursing Journal. 2009; 55-56.

[6] Wolff M, Maurana CA. Building effective community-academic partnerships to improve health: A qualitative study of perspectives from communities. Acad Med [Internet]. 2001; 76(2): 166-72. PMid:11158838 https://doi.org/10.1097/00001888-20010 2000-00016

[7] Plowfield LA, Wheeler EC, Raymond JE. Time, tact, talent, and trust: Essential ingredients of effective academic-community partnerships. Nurs Educ Persp [Internet]. 2005; 26(4): 217-20.

[8] Wilson MG, Lavis JN, Guta A. Community-based organizations in the health sector: A scoping review. Health Res Policy Syst [Internet] 2012; 10. PMid:23171160 https://doi.org/10.1186/1478-4 505-10-36

[9] Drahota A, Meza RD, Brikho B, et al. Community-academic partnerships: A systematic review of the state of the literature and recommendations for future research. Milbank Q [Internet]. 2016; 94(1): 163-214. PMid:26994713 https://doi .org/10.1111/14 68-0009. 12184

[10] Calleson DC, Jordan C, Seifer SD. Community-engaged scholarship: Is faculty work in communities a true academic enter- prise? Acad Med [Internet]. 2005; 80(4): 317-321. PMid:15793012 https://doi.org/10.1097/00001888-200504000-00002

[11] Jassawalla AR, Sashittal HC. An examination of collaboration in high-technology new product development processes. J Prod Innovation Manage [Internet]. 1998; 15(3): 237-54. https ://doi.org/ $10.1111 / 1540-5885.1530237$

[12] Beal JA. Academic-service partnerships in nursing: An integrative review. Nurs Res Pract [Internet]. 2012; 2012: 1-9. PMid:22548160 https://doi.org/10.1155/2012/501564

[13] Buys N, Bursnall S. Establishing university-community partnerships: Processes and benefits. J High Educ Policy Manage [Internet]. 2007; 29(1): 73-86. https://doi.org/10.1080/1360080060117579 7

[14] Mayer K, Braband B, Killen T. Exploring collaboration in a community-academic partnership. Public Health Nurs [Internet]. 2017; 34(6): 541-6. PMid:28762550 https://doi.org/10.111 $1 / \mathrm{phn} .12346$

[15] Social Accountability: A Vision for Canadian Medical Schools [Internet]. Ottawa: Health Canada. 2001 [cited July 5, 2019]. Available from: https://afmc.ca/pdf/pdf_sa_vision_canadian_med ical_schools_en.pdf

[16] Carney JK, Maltby HJ, Mackin KA, et al. Community-academic partnerships: How can communities benefit? Am J Prev Med [Internet]. 2011; 41(4): 206-213. PMid:21961666 https://doi.org/10.1 016/j . amepre.2011.05.020

[17] Entry-to-practice public health nursing competencies for undergraduate nursing education [Internet]. Ottawa $(\mathrm{ON})$ : Canadian Association of Schools of Nursing; c2014 [cited 2019 July 4]. Available from: https://casn.ca/wpcontent/uploads/2014/12/FINA Lpublicheal thcompeENforweb.pdf

[18] Hamilton N, Bhatti T. Population health promotion: An integrated model of population health and health promotion [Internet]. Ottawa (ON). Public Health Agency of Canada; c1996 [cited 2019 July 5]. Available from: https://www.canada.ca/en/public-healt $\mathrm{h} /$ services/health-promotion/population-health/popu lation-health-promotion-integrated-model-populatio n-health-health-promotion.html

[19] Report on the health of Canadians [Internet]. Ottawa (ON): Conference of Deputy Ministers of Health- Minister of Supply and Services Canada; c1996 [cited 2019 July 4]. Available 
from: http://publications.gc.ca/collections/Collect ion/H39-385-1996-1E.pdf

[20] Flynn L. An adaptation of the Hamilton and Bhatti (1996) population health promotion model. Manitoba and Saskatchewan Region:
Health Canada; c1999. [cited 2019 July 4].

[21] Miles MB, Huberman AM. Qualitative data analysis: an expanded sourcebook. Thousand Oaks (CA): Sage Publications; 1994. 